\title{
Full-Scale Manipulation of the Empty Bed Contact Time to Optimize Dissolved Organic Matter Removal by Drinking Water Biofilters
}

Moona, Nashita; Holmes, Andrew; Wunsch, Urban J.; Pettersson, Thomas J. R.; Murphy, Kathleen R.

Published in:

ACS EST Water

Link to article, DOI:

10.1021/acsestwater.0c00105

Publication date:

2021

Document Version

Publisher's PDF, also known as Version of record

Link back to DTU Orbit

Citation (APA):

Moona, N., Holmes, A., Wunsch, U. J., Pettersson, T. J. R., \& Murphy, K. R. (2021). Full-Scale Manipulation of the Empty Bed Contact Time to Optimize Dissolved Organic Matter Removal by Drinking Water Biofilters. ACS EST Water, 1(5), 1117-1126. https://doi.org/10.1021/acsestwater.0c00105

\section{General rights}

Copyright and moral rights for the publications made accessible in the public portal are retained by the authors and/or other copyright owners and it is a condition of accessing publications that users recognise and abide by the legal requirements associated with these rights.

- Users may download and print one copy of any publication from the public portal for the purpose of private study or research.

- You may not further distribute the material or use it for any profit-making activity or commercial gain

- You may freely distribute the URL identifying the publication in the public portal 


\section{Full-Scale Manipulation of the Empty Bed Contact Time to Optimize Dissolved Organic Matter Removal by Drinking Water Biofilters}

Nashita Moona, Andrew Holmes, Urban J. Wünsch, Thomas J. R. Pettersson, and Kathleen R. Murphy*

Cite This: ACS EST Water 2021, 1, 1117-1126

Read Online

ABSTRACT: A study was conducted at a water treatment plant to optimize parallel rapid gravity biofilters for dissolved organic matter (DOM) removal. The biofilters treat urban and agriculturally impacted river water using a commercial non-adsorptive, expandedclay filter medium. The study aimed to locate the optimal operating conditions via experimental manipulation of the biofilter empty bed contact time (EBCT) during full-scale operation at the plant. During a two-month experiment, contact times in four parallel biofilters were switched to and maintained at $15,30,50$, and $80 \mathrm{~min}$ by manipulating the hydraulic loading on each filter. The removal efficiency of organic matter fractions increased with EBCT for

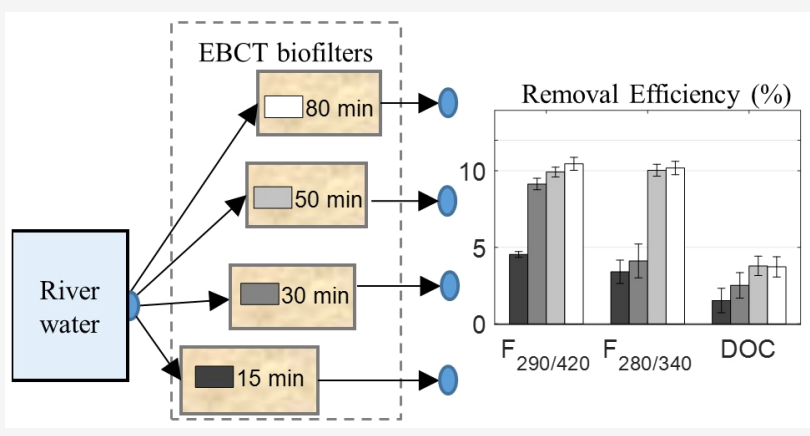
dissolved organic carbon (DOC) and microbial humic-like $\left(\mathrm{F}_{290 / 420}\right)$ and protein-like $\left(\mathrm{F}_{280 / 340}\right)$ fluorescent organic matter. Other DOM fractions were largely unaffected by biofiltration, or at slightly higher concentrations in the effluent. Protein-like fluorescence is associated with labile organic matter fractions, which are known to be removed poorly by drinking water treatment barriers apart from biological filters. The results suggest that long contact times $(>30$ $\mathrm{min}$ ) have advantages for the operation of some biological filters, especially if placed ahead of barriers that are sensitive to biofouling, e.g., membranes.

KEYWORDS: biological filter, drinking water, dissolved organic matter (DOM), fluorescence spectroscopy, parallel factor analysis (PARAFAC), Filtralite

\section{INTRODUCTION}

Drinking waters around the world are produced from raw waters that contain natural organic matter, i.e., organic chemicals derived from living and dead organisms. ${ }^{1}$ Dissolved organic matter (DOM) impacts drinking water treatment, causing problems with process control and optimization and increasing coagulant and disinfectant dose requirements. ${ }^{2}$ DOM further affects drinking water quality by forming carcinogenic disinfection byproducts (DBPs) in combination with chlorine. ${ }^{3}$ DOM that escapes treatment in the plant is a potential substrate for bacterial regrowth in distribution systems, reducing distributed water quality and potentially causing undesirable color, taste, or odor. ${ }^{4}$

Biological filtration is an efficient treatment technology for removing biodegradable DOM compounds. Biofilters serve different purposes in different treatment chains. "Direct" biofilters are mostly used to remove turbidity, particles, and biological organic matter before membrane filtration. Firststage biofilters treat pretreated (e.g., coagulated) water, and second-stage biofilters are used to "polish" prefiltered water. Biofilter performance depends upon multiple factors such as water quality (e.g., DOM concentration and characteristics, $\mathrm{pH}$ and turbidity, and temperature) and design/operation parameters (e.g., type of medium, filtration rate, retention time, and backwash frequency). The position of the filter in the treatment chain also affects performance. First-stage biofilters receiving coagulated water accumulate more flocs and particles during a filtration cycle. ${ }^{5,6}$ In all biofilters, DOM adsorbs onto a naturally occurring biofilm or is biodegraded by microbes living within the biofilm. These biofilm microbes utilize the biodegradable fraction of DOM as a carbon source for their growth, metabolism, and reproduction, yielding effective DOM removal. $^{7}$

The advantages of biologically active rapid gravity filters for producing biologically stable water have been recognized in western Europe since the 1970s. How to optimize second-stage biofilters receiving coagulated water has been studied extensively while focusing on design and water quality parameters. ${ }^{5,8-13}$ Direct biofilters need frequent backwashing to remove turbidity-causing particles, an operation that also removes part of the biofilm. ${ }^{5}$ Thus, direct biofilters have the

Received: August 12, 2020

Revised: March 18, 2021

Accepted: March 19, 2021

Published: April 2, 2021 
contrary process maintenance objectives of removing turbidity, favored by frequent backwashing, and removing biodegradable organic matter, favored by maintaining stable conditions for biomass growth. ${ }^{5}$

Published studies of direct biofiltration involved adsorptive media like granular activated carbon (GAC) or common nonadsorptive filter media, like sand/anthracite. ${ }^{14,15}$ Studies of first-stage full-scale biofilters with expanded clay media are rare. ${ }^{16}$ Filtralite is an expanded clay medium used for many years in Scandinavia in various applications, including for treatment of drinking water, stormwater, industrial wastewaters, ${ }^{17}$ deicing chemicals, ${ }^{18}$ and wastewater. ${ }^{19}$ A majority of studies with a Scandinavian perspective focused on comparing Filtralite filters with anthracite/sand or GAC filters at equal filter depths. ${ }^{20-23}$ We are unaware of any full-scale studies to optimize DOM removal by Filtralite biofilters.

A critical parameter for DOM removal by biofilters is the empty bed contact time (EBCT), i.e., the residence time of the fluid in the filter calculated as though the entire volume of the filter media is occupied by water. Organic matter removal by biofilters can often be improved by increasing the EBCT. It is generally considered that DOM removal increases up to an EBCT of $\sim 30 \mathrm{~min}$, with longer EBCTs having little additional impact. $^{24,25}$ There are also reports that increasing the EBCT beyond $15 \mathrm{~min}$ does not significantly improve effluent water quality. For example, Hasegawa et al. ${ }^{26}$ concluded from column tests that the removal of humic material was unaffected by EBCTs of $>25 \mathrm{~min}$. Hu et al. ${ }^{27}$ reported a $30 \%$ increase in DOC removal by the pilot-scale biofilters when the EBCT was increased from 5 to $30 \mathrm{~min}$, beyond which no improvement was observed. From an operational perspective, long EBCTs require large filters containing more filter media. Because huge amounts of water pass through drinking water treatment plants, a small change in EBCT can have a substantial influence on filtered water volumes. Therefore, the optimum EBCT for organic matter removal must be balanced against water demand and considered at the plant design stage.

Studies to determine optimal EBCTs for DOM removal usually mimic changes in EBCT by sampling a single biofilter at different depths, instead of directly testing removal by identical filters receiving the same water under different flow or loading rates. ${ }^{28,29}$ This affects the validity of the results because the applied shear stress depends on the loading rate, which is constant with depth, whereas changed loading rates create different conditions for biological communities living in the filters. While that issue can be overcome by pilot-scale studies with multiple parallel filter columns, other problems emerge when trying to extrapolate the results of pilot tests to full scale due to geometric, thermodynamic, or kinetic/dynamic dissimilarities. Hence, to compare the influence of EBCT on biological filter operation, it is highly informative to perform experiments at full scale, on parallel systems of biological filters containing media of identical ages, depths, and compositions.

DOM removal by drinking water biofilters is traditionally assessed using bulk parameters like ultraviolet (UV) absorbance at $254 \mathrm{~nm}\left(A_{254}\right)$, specific absorbance (SUVA), color, and total or dissolved organic carbon (TOC or DOC, respectively)..$^{30,31}$ Tracking the removal of different DOM fractions from natural waters is challenging due to a lack of affordable analysis techniques for measuring specific organic matter fractions at the concentrations encountered in surface water. To this end, fluorescence excitation and emission matrix (EEM) spectroscopy is a sensitive technology capable of distinguishing between fractions of fluorescent organic matter in water. ${ }^{32,33}$ Protein-like fractions can be distinguished from humic and fulvic acids, with different subfractions potentially responding differently to biological treatment. ${ }^{13,34,35}$ However, despite its potential for revealing detailed dynamics of DOM removal, fluorescence spectroscopy has yet to be used to study the interaction between EBCT and DOM removal for Filtralite media at batch, pilot, or full scale.

This study examined the role of the EBCT on the DOM removal performance by Filtralite biofilters at full scale. Contact times were manipulated to allow a direct comparison of removal efficiency versus contact time for four parallel biofilters treating identical raw waters under actual operating conditions. This is one of only a few studies of the occurrence, behavior, and removal of fluorescent organic matter in direct Filtralite biofilters and the first of these to manipulate contact times in biofilters at full scale.

\section{METHODS}

Study Site. The study took place during autumn (August 22 to November 5, 2019) at a drinking water treatment plant on the western coast of Sweden. The drinking water treatment plant draws surface water from the river Göta Älv and produces around $9000 \mathrm{~m}^{3}$ of treated water each day, which is around half of its design capacity. Raw water is aerated in an aeration tank and then is split into four parallel rapid gravity biofilters before recombining after the filters. Thereafter, the treatment chain involves direct coagulation onto ultrafilters followed by granular activated carbon filters and UV disinfection. During the study period, water temperatures decreased steadily from 17 to $9{ }^{\circ} \mathrm{C}$ and the turbidity, $\mathrm{pH}$, and DOC were $3.5-15$ NTU, 7.0-7.4, and 3.7-4.4 $\mathrm{mg}$ of $\mathrm{C} \mathrm{L}^{-1}$, respectively, in the raw water following aeration.

Biofilters. The configuration of the parallel rapid gravity biofilters is shown in Figure 1. Each filter has a surface area of $40 \mathrm{~m}^{2}$ ( $4 \mathrm{~m}$ wide by $10 \mathrm{~m}$ long) and is $5 \mathrm{~m}$ deep. A Triton filter bottom system is installed at the bottom of each filter and the filter medium placed directly on top, without any support gravel medium. Each biofilter contained $100 \mathrm{~m}^{3}$ of rather new (<2 year) filtration media (Filtralite Pure Mono-Multi) with a height of approximately $2.5 \mathrm{~m}$. Filtralite is a commercially available expanded clay product made of lightweight porous pulverized clay aggregates. Mono-Multi contains a 50:50 blend of two grades of Filtralite: (1) HC with a $d_{10}$ of $0.8-1.0 \mathrm{~mm}$, a porosity of $53-60 \%$, and a uniformity coefficient of 1.4 and (2) NC with a $d_{10}$ of $1.4-1.6 \mathrm{~mm}$, a porosity of $58-65 \%$, and a uniformity coefficient of 1.3 . By using Filtralite of two different grain sizes and densities, a coarse-to-fine medium filter is established allowing for longer filter run times compared to those of sand/anthracite filters. Despite few adsorption sites compared to GAC, Filtralite is implemented worldwide for biological treatment due to its low price and rough, angular surface with sharp edges and high porosity that provides a larger surface area for microbial growth compared to sand/ anthracite filters. ${ }^{21,36}$

EBCT Manipulation. To evaluate the effect of EBCT on DOM removal efficiency in the biofilters, EBCTs were changed from their initial identical operational conditions to a challenge condition. Initially, EBCTs were nominally $80 \mathrm{~min}$ in each filter, which is the long-term EBCT for this treatment plant. Under challenge conditions, EBCTs were reduced in three filters to approximately 15,30 , or $50 \mathrm{~min}$ (Figure $1 \mathrm{~b}$ ), while the fourth was maintained at $80 \mathrm{~min}$ (reference filter). 
(a)

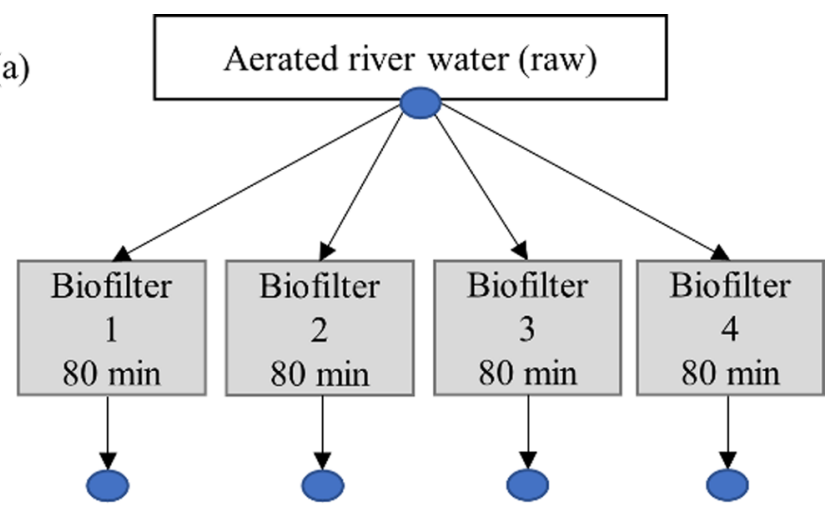

(b)

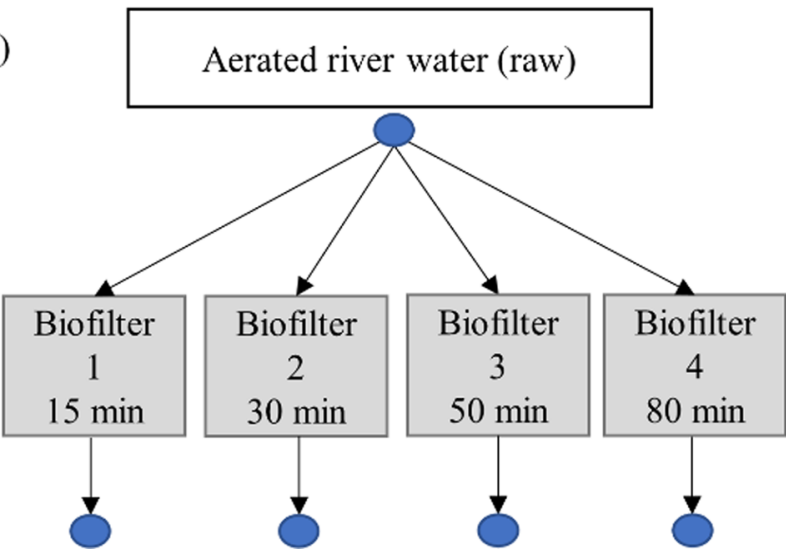

Figure 1. Experimental design showing the configuration of biofilters at the drinking water treatment plant. Blue dots represent sampling locations. (a) Initial EBCTs during normal operations. (b) Manipulated EBCTs during experimental challenge conditions.

Changes in EBCT were achieved by changing the hydraulic loading on the filters as detailed below and documented in the Figure S1.1-S1.4.

Experimental Design and Sampling. During the baseline period before the manipulation of contact times, the average flow rate in each biofilter was approximately $93 \mathrm{~L} \mathrm{~s}^{-1}$, giving a nominal hydraulic filtration rate of $2.1 \mathrm{~m} \mathrm{~h}^{-1}$ and an EBCT of nominally $80 \mathrm{~min}$. However, the typical feed flow rate during this period varied between 100 and $70 \mathrm{~L} \mathrm{~s}^{-1}$ giving rise to a daily variation in hydraulic loading of $1.6-2.25 \mathrm{~m} \mathrm{~h}^{-1}$ corresponding to EBCTs between 93 and 66 min (see Figure S1.1-S1.4).

The contact times were manipulated on September 15 and then maintained under the new conditions for the remainder of the experiment. Under the new conditions, EBCTs fluctuated slightly from their set points but for the sake of simplicity are termed 15, 30, 50, and $80 \mathrm{~min}$ in the text. After manipulation, the filter's head loss was inversely proportional to EBCT; i.e., the filter with the lowest EBCT (15 min EBCT) generated the largest filter head loss. Plots of head loss versus turbidity profiles during the entire experimental period are available in Figure S2.1-S2.4. From these, it is seen that filter head loss profiles were generally less variable during the period of experimental EBCT manipulation than in the baseline period before, although they still responded to periods of increased turbidity in the raw water feed.

Backwashing. The time that has elapsed since backwashing affects filter performance, with filtration efficiency gradually decreasing as sediments accumulate and block pores. In this study to ensure that filters were each sampled under similar conditions, backwashing was performed weekly, within a $4 \mathrm{~h}$ period on the same day for all filters. The backwash procedure consisted of a combination of air $\left(40 \mathrm{~m} \mathrm{~h}^{-1}\right)$ and slow water wash $\left(10 \mathrm{~m} \mathrm{~h}^{-1}\right)$ for $1.5 \mathrm{~min}$. Thereafter, a rapid backwash flow was applied $\left(55 \mathrm{~m} \mathrm{~h}^{-1}\right)$ for $10 \mathrm{~min}$. The filter was then left to stand for $15 \mathrm{~min}$ before filtering to waste for $30 \mathrm{~min}$ or until $300 \mathrm{~m}^{3}$ of filtrate had passed through.

Sampling. Water samples were collected during 16 sampling events. Seven events took place before any changes were made and were used to establish the initial performance of each biofilter, and nine occurred under "challenge conditions" after contact times were manipulated. During each sampling event, samples were collected from five water quality stations (Figure 1, blue dots) representing the single incoming raw water stream (influent) to each of the filters with four different outgoing water streams (effluents). Filtration was performed on site using prewashed $0.2 \mu \mathrm{m}$ Whatman Polycap TC high-capacity capsule filters, with filtrates directed into 250 $\mathrm{mL}$ ashed glass amber bottles. In the lab, these were divided into subsamples, consisting of replicate DOC samples, and individual optical samples.

A spectrophotometer probe (Spectro::lyser i::scan, Messtechnik $\mathrm{GmbH}$ ) monitored turbidity in the filtrates from each filter. The probe was placed in a flow-through chamber, and the effluent from each filter was cycled through the chamber sequentially.

Analytical Methods. Dissolved Organic Carbon and Optical Measurements. DOC was measured by the nonpurgeable organic carbon (NPOC) method using a Shimadzu TOC-VCPH GAC analyzer with autosampler TOC-ASI-V. DOC concentrations were calibrated using a five-point calibration curve for potassium phthalate standard solutions (between 1.0 and $10.0 \mathrm{mg}$ of $\mathrm{C} \mathrm{L}^{-1}$ ) followed by subtraction of a Milli-Q blank. DOC data were presented as the amount of DOC removed $(\triangle \mathrm{DOC}=$ influent $\mathrm{DOC}-$ effluent DOC, milligrams of $\mathrm{C}$ per liter). Initially, two of three DOC replicates were analyzed with the third saved as a backup. The third replicate was always analyzed if the first two did not agree closely (within $\sim 5 \%$ ). Technical problems with the DOC analyzer resulted in the loss of many DOC measurements from samples collected after October 3 (see Table S3.1 for details). This resulted in the loss of several consecutive batches of DOC samples, including several backup samples.

Fluorescence excitation-emission matrices (EEMs) were measured in a $1 \mathrm{~cm}$ cell using a Horiba Aqualog spectrophotometer by scanning the excitation wavelengths from 240 to $500 \mathrm{~nm}$ while detecting emission from 280 to 700 $\mathrm{nm}$. Absorbance measurements were additionally obtained using a UV-vis spectrophotometer (UV-1800, Shimadzu). Processing of fluorescence data followed established methodologies. ${ }^{37}$ Briefly, this included spectral correction, blank subtraction to remove Raman and Rayleigh scatter, and correction for inner filter effects. Fluorescence intensities were normalized to the area under the water Raman peak at $350 \mathrm{~nm}$, thereby converting intensities to Raman units (R.U.).

Three common DOM quality indices were calculated from EEMs: humification index (HIX), a proxy of humic character or degree of humification; fluorescence index (FI), for distinguishing algal and microbial from terrestrial DOM sources; and biological index (BIX), a proxy for the relative importance of biological/microbial DOM. ${ }^{38-40}$ FI correlates with structural conjugation and aromaticity and is widely used 
Table 1. Mean Concentrations ( \pm standard deviation) for Bulk Parameters Measured in Biofilter Influent and Effluent Waters

\begin{tabular}{|c|c|c|c|c|c|}
\hline & influent & & & & \\
\hline EBCT & $0 \mathrm{~min}$ & $15 \mathrm{~min}$ & $30 \mathrm{~min}$ & $50 \mathrm{~min}$ & $80 \mathrm{~min}$ \\
\hline Turbidity (NTU) & $7.60 \pm 0.3$ & $3.48 \pm 1.18$ & $2.97 \pm 0.99$ & $2.00 \pm 1.30$ & $1.22 \pm 1.65$ \\
\hline DOC $\left(\mathrm{mg}\right.$ of $\left.\mathrm{C} \mathrm{L}^{-1}\right)$ & $4.01 \pm 0.27$ & $4.14 \pm 0.2$ & $3.94 \pm 0.47$ & $3.97 \pm 0.29$ & $3.76 \pm 0.22$ \\
\hline$A_{254}\left(\mathrm{~cm}^{-1}\right)$ & $0.13 \pm 0.05$ & $0.15 \pm 0.05$ & $0.14 \pm 0.05$ & $0.14 \pm 0.05$ & $0.14 \pm 0.05$ \\
\hline SUVA $\left[\mathrm{L}(\mathrm{mg} \text { of } \mathrm{C})^{-1} \mathrm{~m}^{-1}\right]$ & $3.20 \pm 0.27$ & $3.60 \pm 0.62$ & $3.40 \pm 0.27$ & $3.40 \pm 0.37$ & $3.00 \pm 0.34$ \\
\hline
\end{tabular}
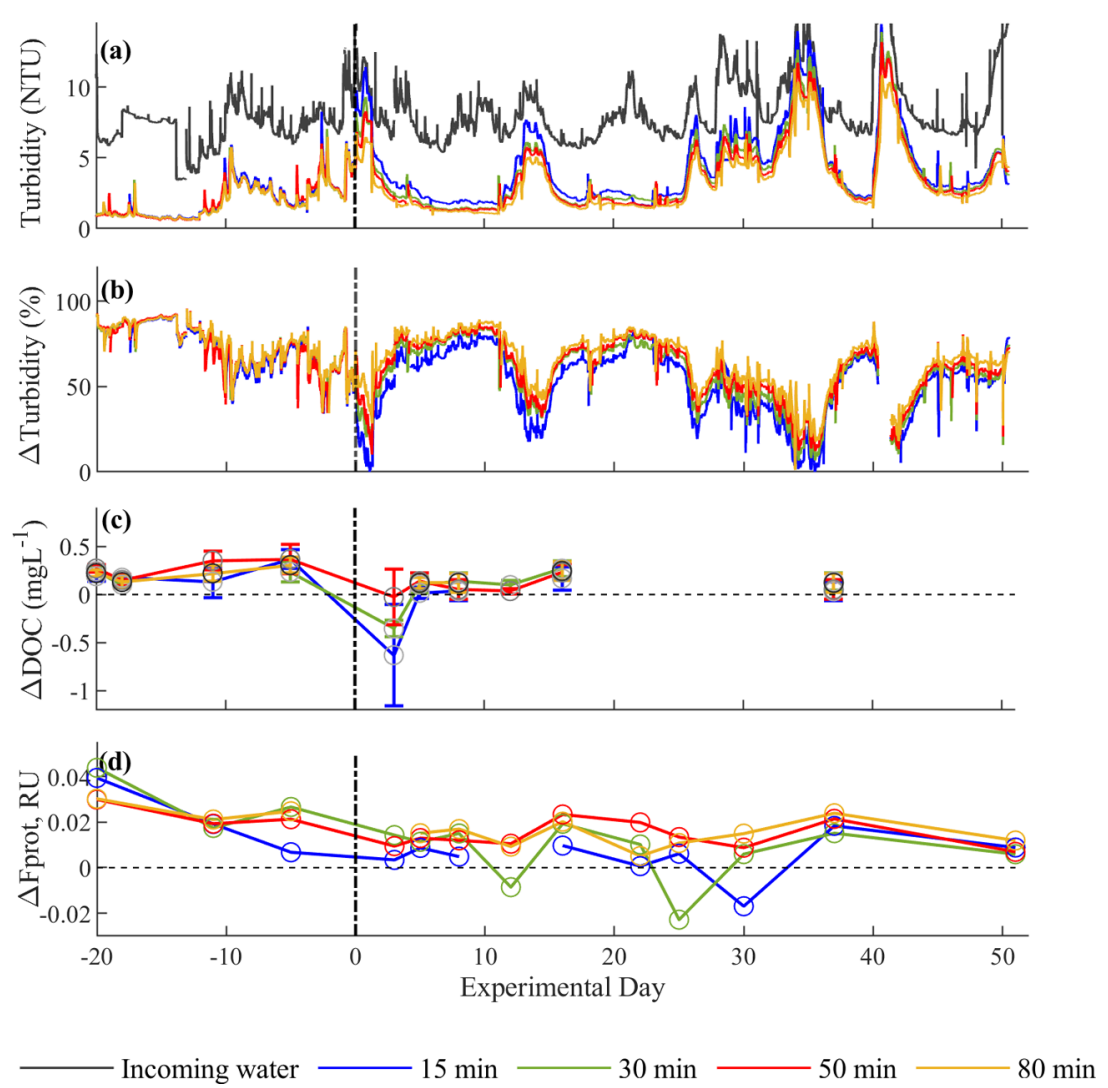

Figure 2. Changes in particulate and dissolved organic matter concentrations over time at varying EBCTs. Vertical dotted lines denote the start of challenge conditions. (a) Turbidity in influent and effluents. (b) Percent turbidity removal. (c) DOC removal. (d) Fluorescence "peak T" removal ( $\lambda_{\mathrm{ex}}$ and $\lambda_{\mathrm{em}}=275$ and $340 \mathrm{~nm}$, respectively). In plots $\mathrm{b}-\mathrm{d}$, values above zero represent removal and values below zero represent production or release. Error bars show standard deviations, with the sample size provided in Table S3.1.

to differentiate DOM sources. Values of $\leq 1.4$ suggest DOM has terrestrial origins with high DOM aromaticity, while values of $\geq 1.9$ suggest microbial sources dominate with lower aromatic carbon content. The BIX or $\beta / \alpha$ index, an indicator of the relative contribution of recently microbially produced DOM, was calculated as the ratio of emission intensity at 380 $\mathrm{nm}(\beta)$ to the maximum emission intensity observed between 420 and $435 \mathrm{~nm}(\alpha)$ for an excitation wavelength of $310 \mathrm{~nm}$. BIX values of $\geq 1$ are interpreted as freshly produced DOM of biological or microbial origin, whereas values of $\leq 0.6$ indicate little biological material.

In today's literature, there are two dominant approaches for estimating the abundance of independently varying fluorescent DOM fractions in drinking water. The most common is peak picking, whereby the maximum intensity of fluorescence (assumed to be proportional to abundance) is extracted at specific wavelength pairs, for example, peak "C" $\left(\lambda_{\mathrm{ex}}\right.$ and $\lambda_{\mathrm{em}}=$ 300-370 and 400-500 $\mathrm{nm}$, respectively) or "T" ( $\lambda_{\mathrm{ex}}$ and $\lambda_{\mathrm{em}}=$ 275 and $340 \mathrm{~nm}$, respectively) in the visible and ultraviolet regions of an EEM, respectively. ${ }^{35}$ A disadvantage of this approach is that data obtained by peak picking are noisy especially when fluorescence intensities are low; furthermore, measured fluorescence at any "picked" wavelength is due to combined signals from several potentially unrelated DOM fractions, especially at visible wavelengths. ${ }^{32}$ In this study, peak picking was used only to track peak " $T$ " representing tryptophan-like fluorescence, because peak $\mathrm{T}$ is used widely as a tracer of biologically derived DOM and emits in part of the EEM that is largely separate from other DOM signals. ${ }^{32}$ Additionally, spectral properties of all independently varying fluorescence fractions were isolated mathematically with parallel factor analysis (PARAFAC) using the drEEM toolbox for MATLAB. ${ }^{41}$ The model was established using EEMs derived from samples collected during the experimental period $(n=79)$ supplemented with EEMs of permeates $(n=17)$ created from passing two samples through three different commercially available solid-phase extraction media (SAX, PPL, and NH2). This latter step has been found to assist PARAFAC by reducing correlations between independent fluorescent subfractions. ${ }^{42}$ Models with three to seven components and non-negative loadings and scores were explored and cross-validated. Ultimately, a split-half validated 

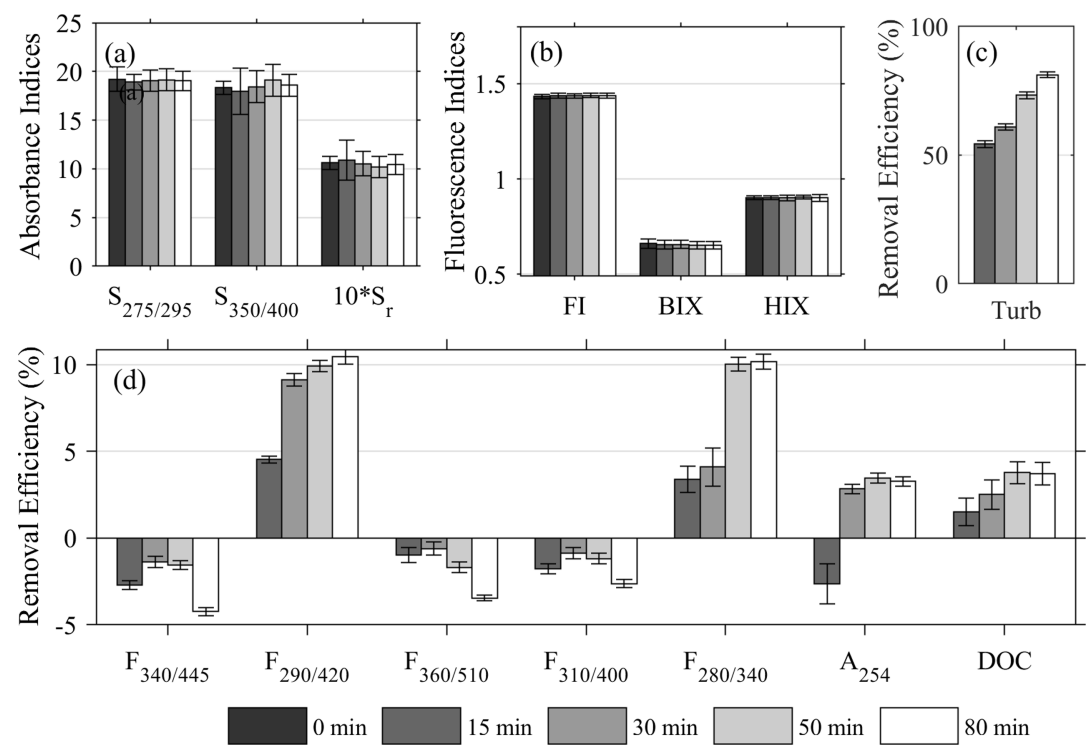

Figure 3. Effect of EBCT on water quality parameters in biofilter influent and effluents during the challenge period: (a) absorbance indices, (b) fluorescence indices, (c) turbidity removal, and (d) removal of optically active DOM fractions and DOC. Shading indicates EBCT; the darkest shade represents influent raw water with a 0 min EBCT, and lighter shades represent effluent water with contact times ranging from 15 min (dark gray) to $80 \mathrm{~min}$ (lightest gray). Error bars represent standard errors of direct measurements (plots a and b) or differences (plots $\mathrm{c}$ and $\mathrm{d}$ ).

five-component PARAFAC model with an explained variance of $99.9 \%$ was found to best represent the data set. Finally, the obtained spectra were compared to those of previously published studies using the OpenFluor database. ${ }^{43}$

Absorbance spectral slopes were calculated for two intervals: 275-295 nm $\left(S_{275 \_295}\right)$ and 350-400 nm $\left(S_{350 \_400}\right)$. In each sample, the spectral slopes of the wavelength intervals, $S_{275} 295$ and $S_{350} 400$, were determined using linear regression of the log-transformed spectra and the slope ratio $\left(S_{R}\right)$ was calculated as $S_{275295}$ divided by $S_{350} 400$. The absorbance at $254 \mathrm{~nm}$ $\left(A_{254}\right)$ was also monitored because it tracks various aromatic compounds. ${ }^{44}$ The specific absorbance (SUVA) was calculated as $A_{254}$ normalized to the DOC concentration and is reported in units of liters per milligram of carbon and meter. ${ }^{30,44}$

Statistical Analysis. All statistical analyses were carried out using MATLAB 9.8 (The MathWorks, Natick, MA). Fluorescence and absorbance measurements were made on unreplicated samples, and outliers representing extreme values compared to the whole data set were removed (partial data for two dates were affected). For DOC measurements with three or more replicates, replicate data that were greater than three scaled median absolute deviations from the median of all other replicates were considered to be outliers and were removed before mean values were determined.

Removals were calculated as the difference between influent $\left(\overline{\mathrm{x}}_{\text {in }}\right)$ and effluent $\left(\overline{\mathrm{x}}_{\text {out }}\right)$ mean concentrations for turbidity, $A_{254}$, and fluorescence peak T. DOC removals were calculated only for dates when there were at least two replicate measurements of both influent and effluent DOC, with standard deviations $(\sigma)$ determined by error propagation (eq 1). Raw data (absolute concentrations) are provided for DOC in Table S3.1.

$$
\bar{x}_{\text {removal }}=\bar{x}_{\text {in }}-\bar{x}_{\text {out }} \text { and } \sigma_{\text {removal }}=\sqrt{{\sigma_{\text {xin }}{ }^{2}+{\sigma_{\text {xout }}}^{2}}^{2}}
$$

\section{RESULTS AND DISCUSSION}

Effect of Contact Time on DOM Removal. Turbidity, DOC, and Protein-like Fluorescence. The mean turbidity, DOC, $A_{254}$, and SUVA for influent and effluent waters are listed in Table 1. In incoming water during the experimental period, the turbidity and DOC were within the ranges of 7.37.9 NTU and $3.8-4.4 \mathrm{mg}$ of $\mathrm{C} \mathrm{L}^{-1}$, respectively, which are typical values for the river Göta $\ddot{A l v}{ }^{45}$ SUVA values were around $3-3.5 \mathrm{~L}(\mathrm{mg} \text { of } \mathrm{C})^{-1} \mathrm{~m}^{-1}$, indicating DOM was moderately aromatic in character. ${ }^{44} A_{254}$ values were in the range of $0.1-0.15 \mathrm{~cm}^{-1}$, which are also typical values for surface water in this region.

Turbidity in water can arise from silt and inorganic and organic particulate matter and potentially includes living organisms. Figure 2a presents online turbidity measurements for both influent and effluent water at different EBCTs during the experimental period. Figure $2 \mathrm{~b}$ presents the turbidity removal efficiency at different EBCTs during the experimental period. A vertical dotted line on the $x$-axis in panels a and $\mathrm{b}$ of Figure 2 represents experimental day 0, i.e., September 15, the date when EBCTs were changed for the challenge experiment.

Turbidity data collected before day 0 (Figure 2a,b) illustrate the effectiveness of Filtralite to eliminate particles and confirm earlier reports. All filters removed turbidity with $\sim 80 \%$ efficiency during this period. When the influent turbidity was high (spikes in the black line in Figure 2a), removal efficiencies decreased for all biofilters because it is generally difficult to remove particles when there is a high particle load. Overall, all of the biofilters were susceptible to particle breakthrough during periods of high influent turbidity ( $>12 \mathrm{NTU})$ and in the $24 \mathrm{~h}$ period immediately following changes in EBCT. From data collected after day 0 , there were two main observations. First, the turbidity removal efficiency was directly proportional to the contact time; i.e., the longer the water was retained in a biofilter, the higher the corresponding removal efficiency. Second, the new turbidity removal efficiencies stabilized quickly after EBCT manipulation. At relatively high influent turbidities, particle removals decreased to almost zero for all biofilters, but otherwise, percent removal was around 10\% lower with a $15 \mathrm{~min}$ EBCT than with an $80 \mathrm{~min}$ EBCT.

The average removal efficiencies at different contact times at a normal influent turbidity ( $\sim 6 \mathrm{NTU})$ ranged from $79 \%$ to 

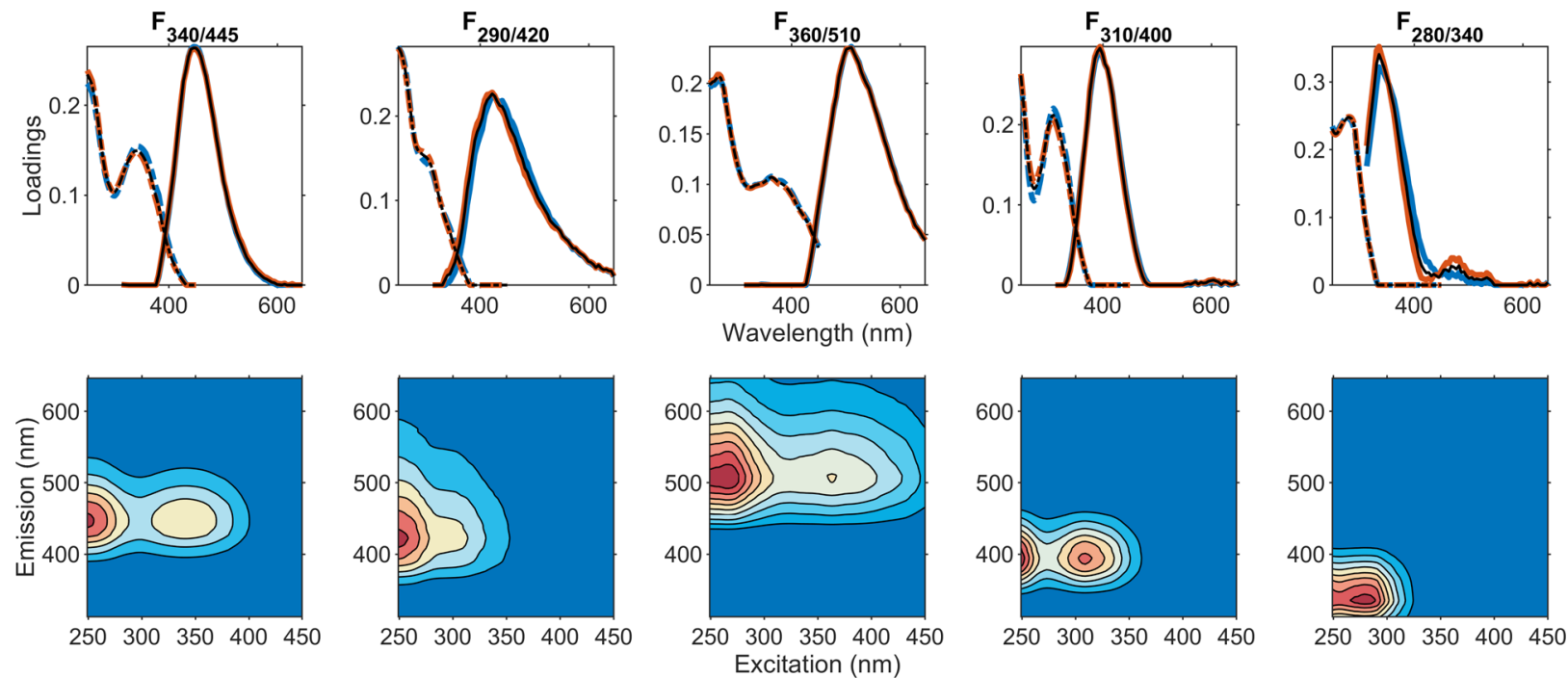

Figure 4. Spectral loadings (top) and fingerprints (bottom) of fluorescent fractions identified using parallel factor analysis. Identical spectra were recovered from the entire data set as from two random data set halves (black, red, and blue lines in the top plots).

$88 \%$, while at a high influent turbidity ( $>9$ NTU), they ranged from $19 \%$ to $46 \%$. With an 80 min EBCT, removal efficiencies were only $9 \%$ higher than with a $15 \mathrm{~min}$ EBCT at a normal influent turbidity compared with $27 \%$ higher at a high influent turbidity ( $>9$ NTU). This suggests a correlation between influent turbidity and relative removal efficiency and indicates that the benefits of longer contact times increase under strained conditions.

DOC removal by Filtralite is primarily due to uptake by biofilm microorganisms that use DOC as a source of carbon. Release of DOC from the biofilters was observed on the sampling occasion immediately after the EBCT change when turbidity removal was still poor (Figure 2c). The measured release was proportional to the change in EBCT; i.e., the filter with the greatest decrease in EBCT showed the greatest DOC release (blue line in Figure 2c). This release was probably caused by the sudden increase in hydraulic loadings and associated disturbance to the established biomass. The spike was followed by an $\sim 30$ day period during which removal of DOC and protein-like fluorescence varied around average values that were inversely related to EBCT (Figure 2c,d).

With a $15 \mathrm{~min}$ EBCT, DOC removal was $\sim 0.06 \mathrm{mg}$ of $\mathrm{C}$ $\mathrm{L}^{-1}$, corresponding to $\sim 1.5 \%$. This is lower than in a pilot-scale study of Filtralite direct filtration by Persson et al. ${ }^{15}$ in which removal of 3-5\% was observed for EBCTs between 12 and 15 min when treating lake water with similar DOC and a turbidity of 0.6-1.2 NTU. DOC removal increased to $2.5-4 \%$ with $30-$ 80 min EBCTs. Long EBCTs are expected to favor biological degradation, by extending the contact period with the biofilm. Previous research showed that the removal of total and dissolved organic carbon, as well as biodegradable and assimilable organic carbon (BDOC and AOC, respectively), increased with EBCT. Melin and Ødegaard ${ }^{21}$ studied the removal of TOC from ozonated influents by pilot-scale upflow Filtralite biofilters and observed $18-37 \%$ removal for an EBCT range of 11-54 min. The higher removal efficiency in that study is probably due mainly to differences in influent water quality, because ozonation produces readily biodegradable compounds, although biofilter design may also play a role (upflow vs downflow). Hu et al. ${ }^{27}$ observed an increase in DOC removal for pilot-scale activated clay and zeolite biofilters from $13 \%$ to $45 \%$ when the EBCT increased from 7.5 to $30 \mathrm{~min}$, but no further benefit after the EBCT increased beyond $30 \mathrm{~min}$.

Absorbance, SUVA, and Slope Ratios. Removal of $A_{254}$ during challenge conditions was $2.8-3.5 \%$ with $30-80 \mathrm{~min}$ EBCTs (Figure $3 \mathrm{~d}$ ), compared to $\sim 2.6 \%$ release at $15 \mathrm{~min}$. $A_{254}$ is a tracer of chromophoric compounds, including both relatively recalcitrant terrestrial (allochthonous) compounds and biologically produced (autochthonous) and relatively labile compounds. SUVA had slightly lower values in the influent and two shorter-EBCT effluents $(\sim 3.3)$ than in the two longer-EBCT effluents $(\sim 3.5)$, although differences were not statistically significant. An increase in SUVA indicates the increasing dominance of aromatic compounds over aliphatic compounds, which is consistent with labile fractions being preferentially removed by biofiltration. Shin et al. ${ }^{46}$ previously reported an increase in SUVA from 2.8 to 4.0 through a bioreactor fed strictly with a fulvic acid carbon source.

The absorbance spectral slope ratio $\left(S_{\mathrm{r}}\right)$ is inversely correlated to the average molecular weight and hence can provide important information about the DOM origin, chemical composition, and source. Molecular weight is an important parameter for biological filtration systems related to bioavailability. Low-molecular weight DOM molecules tend to be more hydrophilic and biolabile, and a high spectral slope, therefore, indicates a preponderance of bioavailable DOM. ${ }^{47,48}$ In biofilter effluents in this study, there were no discernible trends in spectral slopes related to EBCT (Figure 3a).

Fluorescence Intensities and Indices. Fluorescence indices (FI, BIX, and HIX) are widely used to deduce DOM source, allochthonous versus autochthonous origin, and degree of humification. Water with a low FI value $(<1.4)$ is interpreted as having a strong terrestrial source contribution, whereas a high FI value $(>1.8)$ suggests a weak terrestrial influence. Fluorescence data in this study (Figure 3) indicated that the river Göta $\ddot{A l l v}$ was dominated by terrestrial DOM sources, with FI values in influent water $(\sim 1.4)$ nearly unchanged after biofiltration at any EBCT (range of 1.44-1.45). BIX indicates the relative importance of biological/microbial DOM and relative freshness (bioavailability) of the bulk DOM. High BIX values $(>1)$ indicate DOM recently derived from endogenous 
sources, including primary production, whereas low BIX values $(<1)$ indicate aged and condensed terrestrial humics that are easily removed via conventional treatment but not via biological degradation. ${ }^{40,49}$ In this study, BIX ranged between 0.68 and 0.70 , again indicating terrestrially dominated DOM. BIX tended to decrease with an increase in EBCT, but differences between EBCTs were statistically insignificant, which is counter to some earlier reports. ${ }^{50}$ Finally, HIX values that supposedly reflect the degree of humification ranged from 0.87 in raw water to 0.88 in filtered water and showed no trend with an increase in EBCT. Overall, fluorescence indices indicate that the influent water contained mainly aged, relatively humified, terrestrial DOM, which was not very susceptible to biological degradation. At the same time, fluorescence indices barely changed at any contact time and hence were generally insensitive to biofiltration compared to fluorescence intensities (see below). This illustrates the limitations of fluorescence and absorbance indices for tracking subtle changes in water quality and, in particular, for detecting changes in the abundance of labile DOM fractions.

The PARAFAC model of the fluorescence data sets featured five fluorescence components (Figure 4). On the basis of published interpretations of components with similar spectral properties in the OpenFluor database, ${ }^{43}$ the first four components $\left(\mathrm{F}_{340 / 445}, \mathrm{~F}_{290 / 420}, \mathrm{~F}_{360 / 510}\right.$, and $\left.\mathrm{F}_{310 / 400}\right)$ were dominated by visible-wavelength emission as is typical for humic compounds and terrestrially derived DOM. $\mathrm{F}_{290 / 420}$ and $\mathrm{F}_{310 / 400}$ have strongly overlapping spectral properties. Prior studies have concluded that fluorescence spectra in the EEM region where these signals occur represent reprocessed DOM with a recent photochemical ${ }^{33}$ or microbial origin (peak "M"). ${ }^{40}$ The fifth component $\left(\mathrm{F}_{280 / 340}\right)$ emits in the ultraviolet and represents a protein-like (tryptophan-like) component with a recent, probably microbial, origin. It tracks the same fraction as the protein-like " $T$ " peak that was measured by peak picking and is plotted in Figure $2 \mathrm{~d}$, with small intensity differences that can be attributed to the noise-filtering properties of PARAFAC.

Fluorescence intensities of fluorescent DOM fractions identified using PARAFAC analysis provided sensitive data for evaluating biofilter performance (Figure $3 \mathrm{~d}$ and Figure S4.1). Removal efficiencies were negative $(-1 \%$ to $-4 \%)$ for peaks $F_{340 / 445}, F_{360 / 510}$, and $F_{310 / 400}$, indicating a net release of humic-like FDOM occurred from all filters, particularly the 80 min filter (Figure 3d). In contrast, microbial humic-like $\mathrm{F}_{290 / 420}$ and protein-like $\mathrm{F}_{280 / 340}$ were removed at every EBCT with efficiencies of $3.8-11 \%$ for EBCTs of $15-80 \mathrm{~min}$. The effective removal of $\mathrm{F}_{290 / 420}$ and $\mathrm{F}_{280 / 340}$ signals is consistent with the interpretation that these are tracers of labile DOM fractions. Preferential removal of PARAFAC components apparently corresponding to $\mathrm{F}_{290 / 420}$ and $\mathrm{F}_{280 / 340}$ was previously observed in pilot-scale GAC biofiltration tests by Peleato et al. ${ }^{34}$ The much higher removal efficiencies in that study (20-70\% with a 10 min EBCT) compared to the current study ( $<11 \%$ with $15-80$ min EBCTs) probably reflect the different filter media (GAC vs Filtralite) as well as differences in organic matter composition for the raw waters. Similarly, Chen et al. ${ }^{29}$ observed an increase in the removal of proteinlike PARAFAC components (from 5\% to $25 \%$ ) with an increase in EBCT (from 2 to $23 \mathrm{~min}$ ) in the sand/anthracite column biofilters. Because influent DOC in their study ( $\sim 5-9$ $\mathrm{mg}$ of $\left.\mathrm{C} \mathrm{L}^{-1}\right)$ was nearly 2 times higher than in ours (3.6-4.5 mg of $\mathrm{C} \mathrm{L}^{-1}$ ), water quality differences may well have played a role here also.

Earlier studies have used liquid chromatography with organic carbon detection (LC-OCD) to assess biofilter performance at lab scale. In a study by Peleato et al., ${ }^{34}$ the prevalence of biopolymers correlated strongly with the intensity of a PARAFAC component appearing to match $\mathrm{F}_{290 / 420}$; additionally, this component was removed most effectively by biofiltration as was also the case in this study. Huck et al. ${ }^{51}$ and Peldszus et al. ${ }^{52}$ observed that longer contact times (5-14 $\mathrm{min}$ ) led to superior biopolymer removal. Hasegawa et al. ${ }^{26}$ reported that biopolymer removal increased with EBCT up to $15 \mathrm{~min}$; however, they also observed decreased removal at longer EBCTs. They postulated that at contact times of $>15 \mathrm{~min}$, the concentration of biopolymers produced by biofilter microorganisms exceeded the concentration of biopolymers they decomposed. Conversely, the results for $F_{290 / 420}$ in this study suggest that the most effective biopolymer removal occurred in the filters operated with longer contact times $(50-80 \mathrm{~min})$.

The trend observed in this study whereby biofilter efficiency increased with EBCT above $30 \mathrm{~min}$ for at least some tracers is somewhat unexpected given earlier studies that did not observe similar improvements. Data used to calculate average conditions after EBCT change included samples collected as early as 5 days after challenge conditions were implemented. It is possible that the biofilter communities for EBCTs of 15-50 min were acclimating to the changed conditions and performing below their capabilities, particularly in the case of the $15 \mathrm{~min}$ biofilter, and especially during the first days and weeks under challenge conditions. Reported acclimation periods range from a couple of weeks to $>6$ months, with much longer acclimation periods expected when starting up a new biofilter, compared to when changing operational conditions for an established biofilter. ${ }^{53-55}$ Directly comparable studies indicating acclimation times for Filtralite biofilters under modified flow conditions are lacking. While DOC data for 15-50 min filters from the final two sampling occasions in this study may suggest that performance may have been starting to improve (Figure 2), this could not be confirmed using more sensitive tracers. For example, $F_{280 / 340}$ showed the strongest effect of EBCT, with median removal in each filter over the first 3 weeks after challenge conditions began (days $3-22,8.4-11.1 \%)$ either the same as, or less than, median removal in the last 2 weeks (days 25-51, 4.2-10.6\%). However, given the small differences in DOM removal between EBCTs and relatively low signal-to-noise ratios in many of the measured data sets, a longer experiment with more sampling occasions would be needed to thoroughly investigation acclimation. Unfortunately, for operational reasons at the plant in connection with the approaching winter season, it was not feasible to maintain the challenge conditions for more than 51 days.

Relatedly, the DOM removal efficiency at 80 min EBCT was higher in the initial phase of the experiment than under challenge conditions (Table 2). Across all four biofilters operated at an $80 \mathrm{~min}$ EBCT in the first part of the experiment, DOC and $A_{254}$ were removed with $5.7 \%$ and $2.7 \%$ efficiencies on average, respectively. The mean removal efficiency of labile fluorescence fractions was $12.5-14.4 \%$ across all four $80 \mathrm{~min}$ filters initially $(n=13)$, but $<10.5 \%$ under challenge conditions $(n=15)$. We suspect this was due to two factors: (1) decreasing water temperatures, and (2) increasing backwashing 
Table 2. DOM Removal Efficiencies with an $80 \mathrm{~min}$ EBCT (mean \pm standard error) across All Four Biofilters Prior to Beginning the Challenge Experiment

\begin{tabular}{lcc} 
& removal $(\%)$ & $N$ \\
$\mathrm{DOC}$ & $5.71 \pm 0.51$ & 15 \\
$A_{254}$ & $6.07 \pm 1.1$ & 18 \\
$\mathrm{~F}_{340 / 445}$ & $-0.69 \pm 0.28$ & 14 \\
$\mathrm{~F}_{290 / 420}$ & $12.5 \pm 0.21$ & 14 \\
$\mathrm{~F}_{360 / 510}$ & $-0.43 \pm 0.27$ & 13 \\
$\mathrm{~F}_{310 / 400}$ & $0.03 \pm 0.27$ & 14 \\
$\mathrm{~F}_{280 / 340}$ & $14.4 \pm 0.40$ & 14 \\
\hline
\end{tabular}

frequency. First, the influent water temperature decreased from 17 to $9{ }^{\circ} \mathrm{C}$ between late August and early November, decreasing biological activity in the biofilms leading to less biodegradation during the latter part of the experiment. Second, under challenge conditions, all filters were backwashed within $4 \mathrm{~h}$ of each other, with a frequency that was controlled by flushing requirements for the $15 \mathrm{~min}$ filter. Frequent backwashing of the 80 min filter may have eroded the biofilm leading to lower biofiltration efficiency.

\section{CONCLUSION}

Over 2 months, rapid gravity biofilters operating in parallel at a full-scale treatment plant were manipulated to allow a direct comparison of removal efficiency at different EBCTs and hydraulic loadings when treating the same raw water under actual operating conditions. Studies that evaluate full-scale filters operated in parallel are rare yet have significant advantages, especially when compared to studies in which different EBCTs are tested at different times, with different feed waters or at lab scale. The river water was treated directly with biofiltration through Filtralite media using identical biofilters each operated with a different EBCT (15, 30, 50, or $80 \mathrm{~min})$. The performance was compared in terms of removal of turbidity, DOC, and optical parameters (absorbance and fluorescence intensities and ratios). The main conclusions follow.

Direct biofiltration with Filtralite media removed particulate and dissolved organic matter from raw drinking water. Removal efficiencies for various DOM fractions (bulk, chromophoric, and fluorescent) were modest overall $(<15 \%)$, including with an $80 \mathrm{~min} \mathrm{EBCT}$, which represented the longterm acclimation condition for the indigenous biofilms.

Removal efficiencies for DOC, absorbance, and microbial fluorescence signals generally increased with EBCT, with the greatest removal efficiencies observed at 50-80 min.

Chromophoric DOM, represented by $A_{254}$ and tracking autochthonous and allochthonous DOM, was released with a 15 min EBCT and removed with 30-80 min EBCTs with efficiencies of $2.8-6 \%$.

Absorbance spectral slope indices showed no trends with EBCT. Because DOC and fluorescence both indicated a loss of bioavailable molecules through biodegradation, the spectral slope was an insensitive indicator of water quality changes in this study.

Three fluorescence indices (HIX, BIX, and FI) indicated that the raw water source was dominated by terrestrial DOM sources. Because these indices showed no significant differences related to $\mathrm{EBCT}$, they were insensitive indicators of water quality changes.
Efficient removal of $\mathrm{F}_{290 / 420}$ (degraded or processed humiclike) and $\mathrm{F}_{280 / 340}$ (protein-like) indicated that these two components tracked bioavailable DOM fractions. Although the spectral properties of $\mathrm{F}_{290 / 420}$ overlap strongly with those of $\mathrm{F}_{310 / 400}$, the two had different susceptibilities to biofiltration, indicating they tracked compounds with different chemical properties, sources, and bioavailabilities.

Three humic-like DOM fractions $\left(\mathrm{F}_{340 / 445}, \mathrm{~F}_{360 / 510}\right.$, and $\left.\mathrm{F}_{310 / 400}\right)$ were produced in the biofilters. Effluent concentrations exceeded influent concentrations by $<1 \%$ before the EBCT was manipulated, and $\sim 1-4 \%$ at EBCTs ranging from 15 to $80 \mathrm{~min}$ during the challenge experiment.

Overall, the results indicate that long contact times $(>30$ min) can be advantageous for operating biological filters, especially if the biofilter is placed ahead of a treatment barrier that is sensitive to biofouling, e.g., an ultrafiltration or nanofiltration membrane.

It was unclear whether the filters with EBCT 15-50 min had fully acclimated to their changed flow conditions before the end of the experiment. If lengthy acclimation periods are needed, our results may underestimate long-term performance at shorter EBCTs and, correspondingly, overestimate the advantages of longer EBCTs.

\section{ASSOCIATED CONTENT}

\section{Supporting Information}

The Supporting Information is available free of charge at https://pubs.acs.org/doi/10.1021/acsestwater.0c00105.

Plots of hydraulic loading versus EBCT (Figure S1.11.4), hydraulic loading versus head loss and influent turbidity (Figure S2.1-2.4), raw DOC data (Table S3.1), and FDOM time series (Figure S4.1) (PDF)

\section{AUTHOR INFORMATION}

\section{Corresponding Author}

Kathleen R. Murphy - Chalmers University of Technology, Architecture and Civil Engineering, Water Environment Technology, 41296 Gothenburg, Sweden; 이이.org/00000001-5715-3604; Email: murphyk@chalmers.se

\section{Authors}

Nashita Moona - Chalmers University of Technology, Architecture and Civil Engineering, Water Environment Technology, 41296 Gothenburg, Sweden

Andrew Holmes - Kungälvs kommun, 44230 Kungälv, Sweden

Urban J. Wünsch - Technical University of Denmark, National Institute of Aquatic Resources, 2800 Kgs. Lyngby, Denmark

Thomas J. R. Pettersson - Chalmers University of Technology, Architecture and Civil Engineering, Water Environment Technology, 41296 Gothenburg, Sweden

Complete contact information is available at: https://pubs.acs.org/10.1021/acsestwater.0c00105

\section{Author Contributions}

K.R.M., A.H., and N.M. designed the study. A.H. implemented the operations at the plant. N.M. performed laboratory measurements. K.R.M., N.M., and U.J.W. performed data analyses and created visualizations. K.R.M. and N.M. wrote the article. U.J.W. and T.J.R.P. commented on draft versions of the article. All authors approved the final article. 


\section{Notes}

The authors declare no competing financial interest.

All raw and modeled fluorescence and absorbance data (outliers excluded, fully corrected EEMs) as well as model loadings and scores are available as *.mat- and spreadsheet files at https://doi.org/10.11583/DTU.14304104.

\section{ACKNOWLEDGMENTS}

The authors thank Ahmed Mohammed Hagos and Kungälv municipality for operational and technical support during experimental work. We thank Ingemar Heidfors, Johanna Hilding, Thor Wahlberg, Olof Bergstedt, Mia Bondelind, and Johannes Flink for valuable and fruitful discussions. We are grateful to anonymous reviewers for many constructive criticisms of the draft manuscript. Funding for this study was provided by Kungälvs kommun, Purac $A B$, Trollhättan Energi $\mathrm{AB}$, and Sweco Environment AB. N.M. and T.J.R.P. further acknowledge Ph.D. funding provided through the national drinking water research center (DRICKS) hosted at Chalmers University of Technology and supported by the Swedish Water and Wastewater Association (SVU), Göteborg Stad (Kretslopp och Vatten), Västvatten AB, VIVAB, Trollhättan Energi, Sydvatten, and Norrvatten. K.R.M. and U.J.W. acknowledge funding by the Swedish Research Council for Environment, Agricultural Sciences and Spatial Planning (FORMAS Grant 2017-00743).

\section{REFERENCES}

(1) Leenheer, J. A.; Croué, J.-P. Peer Reviewed: Characterizing Aquatic Dissolved Organic Matter. Environ. Sci. Technol. 2003, 37 (1), $18 \mathrm{~A}-26 \mathrm{~A}$.

(2) Matilainen, A.; Gjessing, E. T.; Lahtinen, T.; Hed, L.; Bhatnagar, A.; Sillanpää, M. An overview of the methods used in the characterisation of natural organic matter (NOM) in relation to drinking water treatment. Chemosphere 2011, 83 (11), 1431-1442.

(3) Krasner, S. W.; Weinberg, H. S.; Richardson, S. D.; Pastor, S. J.; Chinn, R.; Sclimenti, M. J.; Onstad, G. D.; Thruston, A. D. Occurrence of a New Generation of Disinfection Byproducts. Environ. Sci. Technol. 2006, 40 (23), 7175-7185.

(4) Singer, P. C. Humic substances as precursors for potentially harmful disinfection by- products. Water Sci. Technol. 1999, 40, 2530.

(5) Niquette, P.; Prévost, M.; Maclean, R. G.; Thibault, D.; Coallier, J.; Desjardins, R.; Lafrance, P. Backwashing first-stage sand-BAC filters. J. - Am. Water Works Assoc. 1998, 90 (1), 86-97.

(6) Ahmad, R.; Amirtharajah, A.; Al-Shawwa, A.; Huck, P. M. Effects of backwashing on biological filters. J. - Am. Water Works Assoc. 1998, 90 (12), 62-73.

(7) Simpson, D. R. Biofilm processes in biologically active carbon water purification. Water Res. 2008, 42 (12), 2839-2848.

(8) Uhl, W. Biofiltration Processes for Organic Matter Removal. Biotechnology 1996, 457.

(9) Urfer, D.; Huck, P. M.; Booth, S. D.; Coffey, B. M. Biological filtration for BOM and particle removal: a critical review. J. - Am. Water Works Assoc. 1997, 89 (12), 83.

(10) Wang, J. Z.; Summers, R. S.; Miltner, R. J. Biofiltration performance: part 1, relationship to biomass. J. - Am. Water Works Assoc. 1995, 87 (12), 55-63.

(11) Basu, O. D.; Dhawan, S.; Black, K. Applications of biofiltration in drinking water treatment-a review. J. Chem. Technol. Biotechnol. 2016, 91 (3), 585-595.

(12) Zhu, I. X.; Getting, T.; Bruce, D. Review of biologically active filters in drinking water applications. J. - Am. Water Works Assoc. 2010, 102 (12), 67-77.

(13) Moona, N.; Wünsch, U. J.; Bondelind, M.; Bergstedt, O.; Sapmaz, T.; Pettersson, T. J.; Murphy, K. R. Temperature-dependent mechanisms of DOM removal by biological activated carbon filters. Environ. Sci.: Water Res. Technol. 2019, No. 5, 2232-2241.

(14) Peldszus, S.; Benecke, J.; Jekel, M.; Huck, P. M. Direct biofiltration pretreatment for fouling control of ultrafiltration membranes. J. - Am. Water Works Assoc. 2012, 104 (7), E430-E445.

(15) Persson, F.; Heinicke, G.; Uhl, W.; Hedberg, T.; Hermansson, M. Performance of direct biofiltration of surface water for reduction of biodegradable organic matter and biofilm formation potential. Environ. Technol. 2006, 27 (9), 1037-1045.

(16) Öhman, S.; Welander, S.; Andersson, S. Fullskaleutvärdering av expanderad lera som filtermaterial i snabbfilter i vattenverk. VAFORSK Rapport 2013, 2013-01.

(17) Nogueira, A.; Bassin, J.; Cerqueira, A.; Dezotti, M. Integration of biofiltration and advanced oxidation processes for tertiary treatment of an oil refinery wastewater aiming at water reuse. Environ. Sci. Pollut. Res. 2016, 23 (10), 9730-9741.

(18) Raspati, G. S.; Lindseth, H. K. H.; Muthanna, T. M.; Azrague, K. Effect of Grain Size and Nutrient Feeding on the Treatment Potential of Biofilters for Treatment of De-Icing Chemicals. Water 2018, 10, 620.

(19) Lindseth, H. K. Investigation of the adsorption and biodegradation capacity of filter media towards airport de-icing chemicals. Master's Thesis, Norwegian University of Science and Technology, Trondheim, Norway, 2016.

(20) Saltnes, T.; Eikebrokk, B.; Ødegaard, H. Contact filtration of humic waters: performance of an expanded clay aggregate filter (Filtralite) compared to a dual anthracite/sand filter. Water Sci. Technol.: Water Supply 2002, 2 (5-6), 17-23.

(21) Melin, E.; Ødegaard, H. Biofiltration of ozonated humic water in expanded clay aggregate filters. Water Sci. Technol. 1999, 40 (9), $165-172$.

(22) Ødegaard, H.; Østerhus, S.; Melin, E.; Eikebrokk, B. NOM removal technologies-Norwegian experiences. Drinking Water Eng. Sci. 2010, 3 (1), 1-9.

(23) Persson, F.; Långmark, J.; Heinicke, G.; Hedberg, T.; Tobiason, J.; Stenström, T.-A.; Hermansson, M. Characterisation of the behaviour of particles in biofilters for pre-treatment of drinking water. Water Res. 2005, 39 (16), 3791-3800.

(24) Sontheimer, H.; Hubele, C. In Use of Ozone and Granular Activated Carbon in Drinking Water Treatment; Second National Conference on Drinking Water, Edmonton, Canada; Pergamon Press: Oxford, U.K., 1987; pp 45-66.

(25) LeChevallier, M. W.; Becker, W. C.; Schorr, P.; Lee, R. G. Evaluating the Performance of Biologically Active Rapid Filters. J. Am. Water Works Assoc. 1992, 84 (4), 136-146.

(26) Hasegawa, S.; Iwamoto, T.; Miyoshi, T.; Onoda, S.; Morita, K.; Takagi, R.; Matsuyama, H. Effect of biological contact filters (BCFs) on membrane fouling in drinking water treatment systems. Water 2017, 9 (12), 981.

(27) Hu, J.; Song, L.; Ong, S.; Phua, E.; Ng, W. Biofiltration pretreatment for reverse osmosis (RO) membrane in a water reclamation system. Chemosphere 2005, 59 (1), 127-133.

(28) Boon, N.; Pycke, B. F.; Marzorati, M.; Hammes, F. Nutrient gradients in a granular activated carbon biofilter drives bacterial community organization and dynamics. Water Res. 2011, 45 (19), 6355-6361.

(29) Chen, F.; Peldszus, S.; Elhadidy, A. M.; Legge, R. L.; Van Dyke, M. I.; Huck, P. M. Kinetics of natural organic matter (NOM) removal during drinking water biofiltration using different NOM characterization approaches. Water Res. 2016, 104, 361-370.

(30) Weishaar, J. L.; Aiken, G. R.; Bergamaschi, B. A.; Fram, M. S.; Fujii, R.; Mopper, K. Evaluation of Specific Ultraviolet Absorbance as an Indicator of the Chemical Composition and Reactivity of Dissolved Organic Carbon. Environ. Sci. Technol. 2003, 37 (20), 4702-4708.

(31) Fu, J.; Lee, W.-N.; Coleman, C.; Nowack, K.; Carter, J.; Huang, C.-H. Removal of disinfection byproduct (DBP) precursors in water by two-stage biofiltration treatment. Water Res. 2017, 123, 224-235. 
(32) Wünsch, U. J.; Bro, R.; Stedmon, C. A.; Wenig, P.; Murphy, K. $\mathrm{R}$. Emerging patterns in the global distribution of dissolved organic matter fluorescence. Anal. Methods 2019, 11 (7), 888-893.

(33) Murphy, K. R.; Timko, S. A.; Gonsior, M.; Powers, L.; Wünsch, U.; Stedmon, C. A. Photochemistry illuminates ubiquitous organic matter fluorescence spectra. Environ. Sci. Technol. 2018, 52 (19), 11243-11250.

(34) Peleato, N. M.; McKie, M.; Taylor-Edmonds, L.; Andrews, S. A.; Legge, R. L.; Andrews, R. C. Fluorescence spectroscopy for monitoring reduction of natural organic matter and halogenated furanone precursors by biofiltration. Chemosphere 2016, 153, 155161.

(35) Henderson, R. K.; Baker, A.; Murphy, K. R.; Hambly, A.; Stuetz, R. M.; Khan, S. J. Fluorescence as a potential monitoring tool for recycled water systems: A review. Water Res. 2009, 43 (4), 863881.

(36) Helmer, C.; Danel, O.; Robin, J.; Brehant, A. Feedbacks on performance tests with filtralite media ${ }^{\circledR}$ compared to conventional media filters at pilot scale; SUEZ - Water Technologies \& Water, 2019.

(37) Murphy, K. R.; Butler, K. D.; Spencer, R. G. M.; Stedmon, C. A.; Boehme, J. R.; Aiken, G. R. Measurement of dissolved organic matter fluorescence in aquatic environments: An interlaboratory comparison. Environ. Sci. Technol. 2010, 44 (24), 9405-9412.

(38) Huguet, A.; Vacher, L.; Relexans, S.; Saubusse, S.; Froidefond, J. M.; Parlanti, E. Properties of fluorescent dissolved organic matter in the Gironde Estuary. Org. Geochem. 2009, 40 (6), 706-719.

(39) Cory, R. M.; McKnight, D. M. Fluorescence spectroscopy reveals ubiquitous presence of oxidized and reduced quinones in dissolved organic matter. Environ. Sci. Technol. 2005, 39 (21), 81428149.

(40) Fellman, J. B.; Hood, E.; Spencer, R. G. Fluorescence spectroscopy opens new windows into dissolved organic matter dynamics in freshwater ecosystems: A review. Limnol. Oceanogr. 2010, 55 (6), 2452-2462.

(41) Murphy, K. R.; Stedmon, C. A.; Graeber, D.; Bro, R. Fluorescence spectroscopy and multi-way techniques. PARAFAC. Anal. Methods 2013, 5, 6557-6566.

(42) Wünsch, U. J.; Murphy, K. A simple method to isolate fluorescence spectra from small dissolved organic matter datasets. Water Res. 2020, 190, 116730.

(43) Murphy, K. R.; Stedmon, C. A.; Wenig, P.; Bro, R. OpenFluoran online spectral library of auto-fluorescence by organic compounds in the environment. Anal. Methods 2014, 6, 658-661.

(44) Edzwald, J. K.; Becker, W. C.; Wattier, K. L. Surrogate parameters for monitoring organic matter and THM precursors. J. Am. Water Works Assoc. 1985, 77, 122-132.

(45) Nikkilä, A.; Paulsson, M.; Almgren, K.; Blanck, H.; Kukkonen, J. V. Atrazine uptake, elimination, and bioconcentration by periphyton communities and Daphnia magna: effects of dissolved organic carbon. Environ. Toxicol. Chem. 2001, 20 (5), 1003-1011.

(46) Shin, H.-S.; Lim, K.-H. Spectroscopic and elemental investigation of microbial decomposition of aquatic fulvic acid in biological process of drinking water treatment. Biodegradation 1996, 7 (4), 287-295.

(47) Baghoth, S. A.; Sharma, S. K.; Amy, G. L. Tracking natural organic matter (NOM) in a drinking water treatment plant using fluorescence excitation-emission matrices and PARAFAC. Water Res. 2011, 45 (2), 797-809.

(48) Hammes, F.; Salhi, E.; Köster, O.; Kaiser, H.-P.; Egli, T.; Von Gunten, U. Mechanistic and kinetic evaluation of organic disinfection by-product and assimilable organic carbon (AOC) formation during the ozonation of drinking water. Water Res. 2006, 40 (12), 22752286.

(49) Birdwell, J. E.; Engel, A. S. Characterization of dissolved organic matter in cave and spring waters using UV-Vis absorbance and fluorescence spectroscopy. Org. Geochem. 2010, 41 (3), 270-280.

(50) Lavonen, E. E.; Kothawala, D. N.; Tranvik, L. J.; Gonsior, M.; Schmitt-Kopplin, P.; Kohler, S. J. Tracking changes in the optical properties and molecular composition of dissolved organic matter during drinking water production. Water Res. 2015, 85, 286.

(51) Huck, P. M.; Peldszus, S.; Haberkamp, J.; Jekel, M. Assessing the performance of biological filtration as pretreatment to low pressure membranes for drinking water. Environ. Sci. Technol. 2009, 43 (10), 3878-3884.

(52) Peldszus, S.; Hallé, C.; Peiris, R. H.; Hamouda, M.; Jin, X.; Legge, R. L.; Budman, H.; Moresoli, C.; Huck, P. M. Reversible and irreversible low-pressure membrane foulants in drinking water treatment: Identification by principal component analysis of fluorescence EEM and mitigation by biofiltration pretreatment. Water Res. 2011, 45 (16), 5161-5170.

(53) Brown, J.; Upadhyaya, G.; Carter, J.; Brown, T.; Lauderdale, C. North American biofiltration knowledge base, project number: 4459. Water Research Foundation, 2016; Vol. 7, p 7.

(54) Carlson, K. H.; Amy, G. L. BOM removal during biofiltration. J. - Am. Water Works Assoc. 1998, 90 (12), 42-52.

(55) Liu, X.; Huck, P. M.; Slawson, R. M. Factors affecting drinking water biofiltration. J. - Am. Water Works Assoc. 2001, 93 (12), 90101. 